\title{
Laparoscopic radical prostatectomy with bladder neck preservation: positive surgical margin and urinary continence status
}

\author{
Tomasz Golabek ${ }^{1}$, Jaroslaw Jaskulski ${ }^{2}$, Piotr Jarecki ${ }^{3}$, Przemysław Dudek ${ }^{1}$, Tomasz Szopiński ${ }^{1}$, Piotr Chłosta ${ }^{1}$ \\ ${ }^{1}$ Department of Urology, Jagiellonian University Medical College, Krakow, Poland \\ ${ }^{2}$ Department of Urology, Institute of Oncology, Kielce, Poland \\ ${ }^{3}$ Department of Urology, City Hospital, Koscierzyna, Poland
}

Videosurgery Miniinv 2014; 9 (3): 362-370

DOI: $10.5114 /$ wiitm.2014.45085

\begin{abstract}
Introduction: Preservation of the bladder neck (BN) has been controversial, as limited excision of the bladder neck may result in incomplete resection of the disease. Moreover, the urinary continence rate may not be improved.

Aim: To evaluate the effect of bladder neck sparing on urinary continence, and surgical margins status in prostate cancer ( $P C$ a) patients treated with laparoscopic radical extraperitoneal prostatectomy.

Material and methods: A retrospective analysis of 295 consecutive patients who had undergone laparoscopic radical extraperitoneal prostatectomy for clinically localised prostate cancer in a single institution was performed. Positive surgical margin $(S M(+))$ and urinary continence status at 3, 6, and 12 months were evaluated.

Results: The distribution of SM(+) for pT2, pT3, and pT4a was 15.3\% (27/176), 49.1\% (58/118), and 100\% (1/1), respectively. Overall, there were $55.61 \%, 80.61 \%$, and $84.69 \%$ of men continent at 3, 6, and 12 months, respectively. However, when limiting the analysis to those who did not receive adjuvant radiotherapy within 12 months following surgery, urinary continence rates were 59.23\%, 85.86\%, and $90.21 \%$ at 3, 6, and 12 months, respectively. Preoperative prostate-specific antigen (PSA) and pathological $T$ stage were identified as significant predictors of positive surgical margins.

Conclusions: Laparoscopic radical extraperitoneal prostatectomy with bladder neck preservation has been a safe procedure which has resulted in good functional outcome. We observed a relatively high incidence of positive surgical margins which could be attributed to a large number of extracapsular disease cases.
\end{abstract}

Key words: laparoscopic radical prostatectomy, bladder neck preservation, surgical margin, urinary continence.

\section{Introduction}

Radical prostatectomy is considered the "gold standard" treatment for patients with localised prostate cancer and life expectancy greater than 10 years [1]. Regardless of the technique of the procedure being performed, its primary goal remains to achieve excellent cancer control. However, this has to be balanced against the morbidities including urinary incontinence and quality of life [1-5]. With the intent of reducing the invasiveness of an open approach, in 1991 Schuessler et al. performed the first laparoscopic prostatectomy [6]. Since then the shift from open to endoscopic surgery has begun, as the minimally invasive techniques offer magnification of the operative field and enable more precise identification and dissection of the anatomical structures [7-9]. However, even with the advancement of laparoscopic and robotic surgery, the likelihood of post-prostatectomy urinary incontinence may be

\section{Address for correspondence}

Tomasz Golabek MD, PhD, Department of Urology, Jagiellonian University Medical College, 18 Grzegorzecka St, $31-531$ Krakow,

Poland, phone: +48 690999 122, e-mail: elementare@op.pl 
high and ranges, depending on the definition of urinary control, from $2.5 \%$ to $87 \%$ [10]. To improve the functional outcomes of the surgery, several different centres across the world have developed more refined techniques which allow for nerve sparing, apical dissection and bladder neck preservation (BNP) [7, 11, 12]. However, BNP remains controversial, as it may come at the cost of high risk of positive surgical margins, compromising the disease prognosis, and not necessarily being able to guarantee a better continence outcome $[13,14]$.

\section{Aim}

Therefore, the aim of this study is to evaluate the effect of bladder neck sparing on urinary continence and surgical margins status in prostate cancer patients treated with laparoscopic radical extraperitoneal prostatectomy.

\section{Material and methods}

Clinical and histological data of 295 consecutive patients, who had undergone laparoscopic radical extraperitoneal prostatectomy (LRP) for clinically localised prostate cancer in a single institution, between January 2007 and December 2012, were reviewed from a prospectively maintained database. All of the procedures were performed by two experienced surgeons. Bladder neck preservation technique was applied with a bladder neck circumference approximating the urethral stump before anastomosis, as previously described $[7,8]$. As BN sparing was performed consistently, we did not exclude patients with median lobe hypertrophy or those with high-risk features from this bladder neck dissection technique. All pathological examinations were performed by a single pathologist. A positive surgical margin was defined as the presence of cancer cells at the inked margin of the resected specimen.

Perioperative parameters such as operative time, transfusion and conversion rates, catheterisation time, pathological results and positive surgical margin rates were reviewed from our prospectively maintained database. Urinary continence status was assessed with the ICIQ-UI Short Form questionnaire at 3, 6 and 12 months after every laparoscopic radical prostatectomy [15]. Postoperative continence was defined as the absence of need for any pads. Patients who had less than 12 months of follow-up were excluded from the postoperative continence status analysis. A total of 196 men met these inclusion criteria and were analysed respectively. Follow-up comprised clinical examination and evaluation of the PSA levels at 3, 6, 9 and 12 months after laparoscopic radical prostatectomy and every 6 months thereafter. Biochemical recurrence (BCR) was defined as two consecutive PSA levels of $>0.2 \mathrm{ng} /$ $\mathrm{ml}$ after LRP.

\section{Statistical analysis}

The Shapiro-Wilk test was used to examine for normal distribution. Results were presented as mean values \pm standard deviation $( \pm S D$ ) when data were normally distributed, otherwise as median, $1^{\text {st }}$ and $3^{\text {rd }}$ quartile (Q1, Q3). Parametric $t$ test and Mann-Whitney $U$ tests were applied as appropriate. The associations between parameters were examined using Spearman's rank correlation coefficient. Kaplan-Meier method and the log rank test were used for biochemical recurrence-free survival analyses. For all statistical tests a $p$ value $<0.05$ was considered statistically significant. The Statistical Package for the Social Sciences (SPSS), version 19, was used for all statistical analyses.

\section{Results}

Patient demographic data are presented in Table I and intraoperative data in Table II. The mean patient age was 62 years (range: $42-78$ years). The most common preoperative Gleason score was 6 .

Table I. Patient demographics

\begin{tabular}{|lc|}
\hline Variable & Value \\
\hline Age, mean \pm SD [years] & $62 \pm 6.40$ \\
\hline PSA, mean \pm SD $[\mathrm{ng} / \mathrm{ml}]$ & $10.38 \pm 12.21$ \\
\hline Median Gleason score & 6 \\
\hline Preoperative Gleason score [\%]: & 9 \\
\hline 4 & 16 \\
\hline 5 & 47 \\
\hline 6 & 22 \\
\hline 7 & 3 \\
\hline 9 & 3 \\
\hline
\end{tabular}


Table II. Intraoperative data

\begin{tabular}{|lc|}
\hline Variable & Value \\
\hline Operative time, mean \pm SD [min] & $156 \pm 47$ \\
\hline Transfusion rate (\%) & 1.3 \\
\hline Conversion rate (\%) & 1.6 \\
\hline LOS, mean \pm SD [days] & $8.05 \pm 2.80$ \\
\hline Catheterisation time, mean \pm SD [days] & $19.23 \pm 5.68$ \\
\hline LOS - length of hospital stay &
\end{tabular}

Mean operative time (from skin incision to skin closure) was $156 \mathrm{~min}$ (range: 85-370 $\mathrm{min}$ ). The total perioperative transfusion rate was $3.7 \%$, and the intraoperative transfusion rate was $1.3 \%$ (4 patients required blood transfusion during surgery). Five patients required conversion to an open procedure: one occurred in an obese man due to the lack of extra-long instruments and the inability to perform anastomotic suturing; two others were due to suboptimal vision due to camera malfunction; and two cases were converted to open surgery due to problems with the gas insufflator and the inability to maintain adequate intra-abdominal pressure.

There were no intraoperative complications. The mean hospital stay was 8 days (range: 2-14 days) and the mean catheter time was 19 days (range: 9-36 days). The median follow-up was 36 months (range: 12-60 months).

Oncologic results are presented in Table III. The most common Gleason score determined postoperatively was 6 . The distribution of pathologic stages was $59.7 \%$ pT2, $40.0 \%$ pT3 and $0.3 \%$ pT4. The overall positive surgical margin rate was $29.15 \%$ (86 cases). Of those, 30.2\% (27/86) were observed in men with pT2 stage of prostate cancer, $67.4 \%$ $(58 / 86)$ were detected in patients with pT3 stage, and $1.16 \%(1 / 86)$ of $S M(+)$ was noted in a man with pT4a disease. The distribution of SM(+) for pT2, pT3, and pT4a was 15.3\% (27/176), 49.1\% (58/118), and $100 \%(1 / 1)$, respectively.

Overall, 59 patients (20.0\%) had an isolated SM(+) and 27 men (13.7\%) had multiple positive margins. Of those, $29.0 \%$ of patients (25/86) had a solitary apical SM(+), whereas an isolated positive surgical margin was present in posterolateral, posterior, lateral and anterior location in 16.3\% (14/86), $12.8 \%$ (11), $4.7 \%$ (4/86), and 3.5\% (3/86) of cases, respectively.
Table III. Oncologic results

\begin{tabular}{|c|c|}
\hline Variable & Value \\
\hline pT2a, n (\%) & $40(13.6)$ \\
\hline pT2b, n (\%) & $15(5.1)$ \\
\hline pT2c, $n(\%)$ & $121(41.0)$ \\
\hline pT3a, n (\%) & $96(32.0)$ \\
\hline pT3b, n (\%) & $22(7.5)$ \\
\hline pT4a, $n(\%)$ & $1(0.3)$ \\
\hline Median Gleason score & 6 \\
\hline \multicolumn{2}{|c|}{ Postoperative Gleason score (\%): } \\
\hline 4 & 5.1 \\
\hline 5 & 18.9 \\
\hline 6 & 38.3 \\
\hline 7 & 30.2 \\
\hline 8 & 4.1 \\
\hline 9 & 3.4 \\
\hline Overall SM(+), $n(\%)$ & $86(29.15)$ \\
\hline \multicolumn{2}{|l|}{ SM(+) by stage: } \\
\hline pT2a, n (\%) & $2(5.0)$ \\
\hline pT2b, $n(\%)$ & $4(26.6)$ \\
\hline pT2c, $n(\%)$ & $21(17.3)$ \\
\hline pT3a, $n(\%)$ & $44(45.8)$ \\
\hline pT3b, $n(\%)$ & $14(63.6)$ \\
\hline pT4a, $n(\%)$ & $1(100)$ \\
\hline
\end{tabular}

$S M(+)$ - positive surgical margin

The bladder neck was a positive margin in 14 instances $(16.3 \%)$, and in 12 out of those cases $(85.7 \%)$ it was in combination with an $\mathrm{SM}(+)$ at 1 or 2 other sites (apex in 6 men, anterior in 4 cases, and posterolateral in 4 patients).

Postoperative urinary continence status was assessed in 196 patients at 3, 6 and 12 months after surgery (Table IV). Overall, there were $55.61 \%$, 80.61\%, and $84.69 \%$ of men continent, respectively. However, when limiting the analysis to those who did not receive adjuvant radiotherapy within 12 months following surgery (184 men), urinary continence rates were $59.23 \%, 85.86 \%$, and $90.21 \%$ at 3,6 , and 12 months, respectively. 
Overall, detectable prostate-specific antigen levels of $>0.20 \mathrm{ng} / \mathrm{ml}$ were found in 14 patients (7.1\%). Six cases were detected in patients with negative surgical margins $(\mathrm{SM}(-))(2.8 \%$ of the $\mathrm{SM}(-)$ group), and 8 men had positive SM $(9.3 \%$ of the $S M(+)$ group). The mean time to detectable PSA recurrence was 22.05 months in patients with negative surgical margins and 18.17 months in men with positive surgical margins, $p=0.182$. The overall biochemical recurrence-free survival rate was $74.2 \%(141 / 190)$ at 3 years.

Four patients developed bone metastases. Of those, 3 had $\mathrm{SM}(-)$ and 1 had $\mathrm{SM}(+)$. The median time to a positive bone scan was 40 months.

Adjuvant or salvage radiation treatment (RXT) was provided to 57 men during 3 years of follow-up. Of those, 12 underwent radiotherapy during the first 12 months of follow-up, 17 men had RXT between 12 and 24 months following surgery, and 28 patients received radiation treatment in the third year of follow-up. For patients with presumed local recurrence ( 2 cases) who refused RXT, expectant management was offered. Men with a systematic relapse were managed with androgen deprivation treatment.

The surgical margin status was significantly correlated with the preoperative PSA $(p=0.008)$, clinical T stage $(p=0.006)$, and pathological T stage $(p<$ $0.001)$. Patients with positive surgical margins more commonly had a lesion staged as $\mathrm{cT} 2 \mathrm{~b}$ and, less frequently, a tumour determined as CT2a on digital rectal examination than men with negative surgical margins $(15.1 \%$ and $20.9 \%$ vs. $33.0 \%$ and $11.0 \%$, respectively). Moreover, a higher pathological T stage of prostate cancer ( $\mathrm{pT} 3 \mathrm{a}$ and $\mathrm{pT} 3 \mathrm{~b}$ ) was observed more frequently in men with $\mathrm{SM}(+)$ compared to those with SM(-) $(51.1 \%$ and $16.3 \%$ vs. $24.9 \%$ and $4.3 \%$, respectively). Preoperative median PSA level in patients with negative surgical margins was lower than in cases with $\mathrm{SM}(+)(7.70 \mathrm{ng} / \mathrm{ml}(5.55 ; 10.80)$ vs. $8.38 \mathrm{ng} / \mathrm{ml}$ (6.87; 11.81), respectively).

There was no statistical difference in the age of patients when analysed by the status of surgical margins (61.85 \pm 6.08 years in men with negative $S M$, and $62.79 \pm 7.07$ years in men with $S M(+), p=$ 0.249). Similarly, there was no statistical difference observed in the median biopsy and postoperative Gleason score when analysed by the SM status (the median biopsy and postoperative Gleason score in both groups of men was $6, p=0.639$, and $p=$ 0.071 , respectively). To further evaluate a possible
Table IV. Postoperative continence rates with $(\mathrm{RXT}+)$ and without adjuvant radiotherapy (RXT-)

\begin{tabular}{|ccc|}
\hline $\begin{array}{c}\text { Postoperative } \\
\text { time [months] }\end{array}$ & $\begin{array}{c}\text { Continence rate } \\
(\mathrm{RXT}+)(\%)\end{array}$ & $\begin{array}{c}\text { Continence rate } \\
(\mathrm{RXT}-)(\%)\end{array}$ \\
\hline 3 & 55.61 & 59.23 \\
\hline 6 & 80.61 & 85.86 \\
\hline 12 & 84.69 & 90.21 \\
\hline
\end{tabular}

Continence rate $(R X T+)$ - continence rates of all patients including those who underwent adjuvant radiotherapy, continence rate (RXT-) - continence rates of patients who did not receive adjuvant radiotherapy

association of Gleason score with surgical margin status, we also analysed outcomes by Gleason score into low, intermediate or high grades based on the Gleason score of 4-6, 7, and 8-10, respectively. This analysis identified no statistical difference in the frequency of those three biopsy and postoperative grades in men with $\mathrm{SM}(+)$ and $\mathrm{SM}(-)(p=0.450$, and $p=0.162$, respectively).

The logistic regression analysis indicated that preoperative PSA, and pathological $T$ stage correlated with positive surgical margin ( $p=0.008, r=$ 0.154 , and $p<0.001, r=0.371$, respectively). There was no correlation between surgical margin status and the biopsy and postoperative Gleason score, or clinical T stage.

Surgical margin status had a significant effect on the 3-year biochemical recurrence-free survival, with a higher percentage of men without PSA recurrence in those with negative surgical margins (89.9\% vs. $55.8 \%$, respectively, $p<0.001$ ) (Figure 1 ).

To evaluate the prognostic value of preoperative PSA, we divided the patients with and without positive surgical margins into those with PSA $\leq 10 \mathrm{ng} /$ $\mathrm{ml}$, and > $10 \mathrm{ng} / \mathrm{ml}$. Men with PSA > $10 \mathrm{ng} / \mathrm{ml}$ had significantly shorter time to biochemical recurrence (83.3\% vs. $92.3 \%$ in cases with $\mathrm{SM}(-)$, respectively, $p=0.047$, and $39.2 \%$ versus $65.4 \%$ in patients with $\mathrm{SM}(+)$, respectively, $p=0.027$ ) (Figures 2 and 3 ).

\section{Discussion}

Urinary continence in men depends on the coordinated function of two independent sphincter mechanisms, which are the proximal urethral sphincter, located within the bladder neck, and the distal urethral sphincter, anchored below the verumontanum $[16,17]$. Injury to either one can result in the loss of urinary control $[18,19]$. 


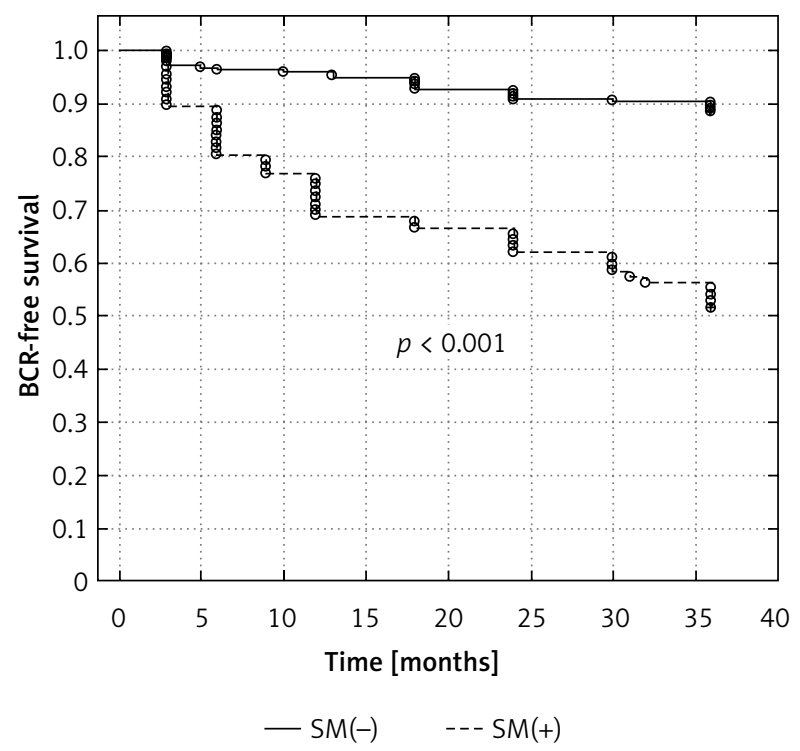

Figure 1. Kaplan-Meier curve showing the biochemical recurrence-free survival rates (progression PSA greater than $0.2 \mathrm{ng} / \mathrm{ml}$ ) according to surgical margin status

$B C R$-free survival - biochemical recurrence-free survival; $S M(+)$ - positive surgical margin, SM(-) - negative surgical margin, PSA - prostate-specific antigen

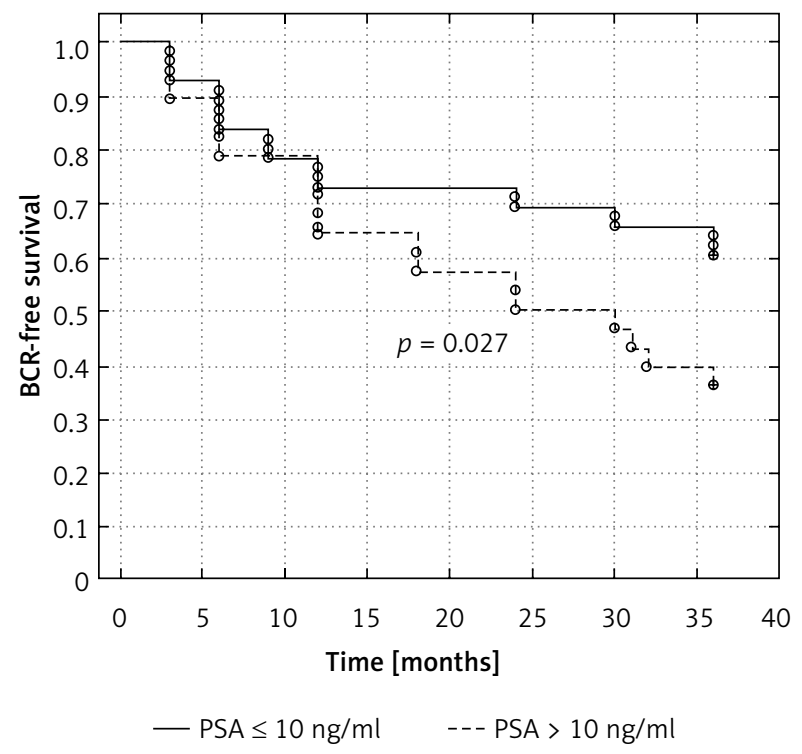

Figure 3. Kaplan-Meier curve showing biochemical recurrence-free survival rates (progression PSA greater than $0.2 \mathrm{ng} / \mathrm{ml}$ ) according to preoperative PSA strata in men with positive surgical margin

$B C R$-free survival - biochemical recurrence-free survival, PSA - prostate-specific antigen

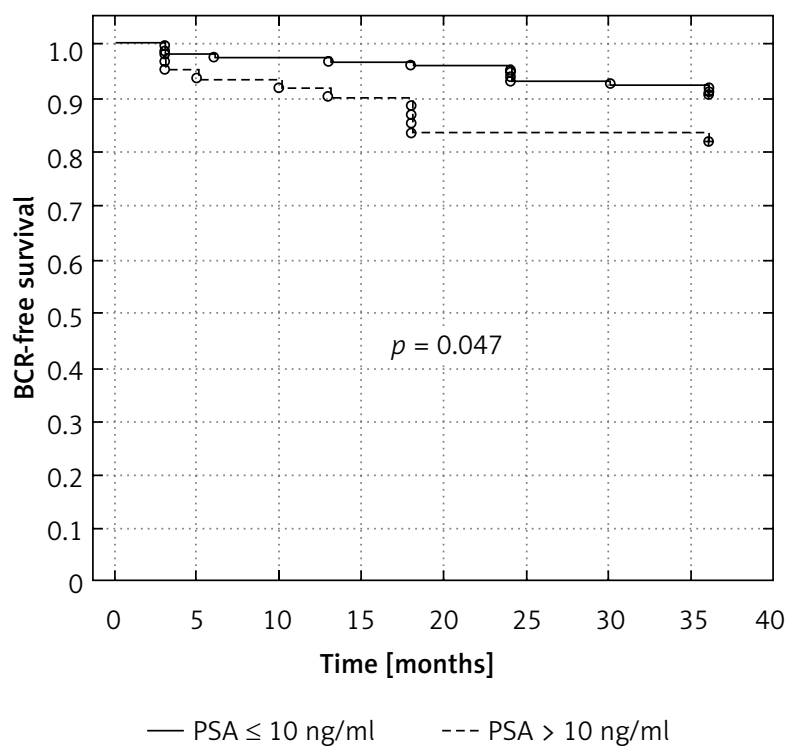

Figure 2. Kaplan-Meier curve showing biochemical recurrence-free survival rates (progression PSA greater than $0.2 \mathrm{ng} / \mathrm{ml}$ ) according to preoperative PSA strata in men with negative surgical margin

$B C R$-free survival - biochemical recurrence-free survival, PSA - prostate-specific antigen

Radical prostatectomy, which most commonly leads to bladder neck dysfunction, may also cause intraoperative damage of the neuronal innervation, which itself can adversely affect the continence mechanisms $[18,20]$. In order to preserve these critical structures, and consequently improve functional outcome, various technical modifications have been introduced, including neurovascular bundle and bladder neck preservation [7, 11, 12]. However, despite BNP during radical prostatectomy being performed for more than 20 years, it still remains unclear how this technical refinement affects urinary continence, particularly in the long term, but more importantly whether or not it carries a risk for the positive surgical margins $[10,11,21]$.

In our study, overall urinary continence rates at 3, 6, and 12 months were $55.61 \%, 80.61 \%$, and $84.69 \%$, respectively. However, this analysis included data from incontinent men who had adjuvant radiotherapy within 12 months of surgery. To eliminate a potential bias, associated with an adverse radiotherapeutic effect on the continence mechanisms, we excluded those patients from the analysis. The resultant data showed greater continence rates at 
all 3 points of assessment $(59.23 \%, 85.86 \%$, and $90.21 \%$ at 3, 6, and 12 months, respectively). These results are comparable with current literature $[4,7$, 22, 23].

Bladder neck preservation carries a potential risk for positive surgical margins as limited excision of the bladder neck may result in the incomplete resection of the disease. In our study, the overall SM(+) rate was $29.15 \%$. The distribution of $\mathrm{SM}(+)$ for $\mathrm{pT} 2$, pT3, and pT4a was 15.3\% (27/176), 49.1\% (58/118), and $100 \%(1 / 1)$, respectively.

Several previous studies have addressed the risk of $\mathrm{SM}(+)$ after LRP. A positive surgical margin rate of $16.6 \%$ to $39.4 \%$ has been reported $[24,25]$. In studies evaluating the effect of bladder neck preservation on tumour resection, the overall $\mathrm{SM}(+)$ rate was up to $32 \%$ [25]. A review of 555 radical prostatectomies found the presence of positive surgical margins in $32 \%$ of patients [26]. In that study $54 \%$ of men with extracapsular extension of the disease had SM(+). Deliveliotis et al. reported a $21 \%$ incidence of $\mathrm{SM}(+)$ in patients who underwent radical prostatectomy with a BNP procedure, whereas Poon et al. described a $27.4 \%$ positive surgical margin rate with bladder neck preservation $[27,28]$. Similarly, a recent report from the U.K., which evaluated the oncological results in 575 patients who underwent endoscopic extraperitoneal radical prostatectomy, identified 135 men (23.5\%) with positive surgical margins [29]. The SM(+) rate for pT2 disease was $66 / 406$ patients (16.3\%) and for pT3 disease it was 68/168 patients (40.5\%). Terakawa et al. reported an overall positive surgical margin rate of $39.4 \%$, with a rate of $30.2 \%$ found in patients with pT2 disease and $71.0 \%$ in patients with pT3 disease [25].

However, several studies evaluating the oncological outcome of laparoscopic and robotic radical prostatectomies found lower rates of $\operatorname{SM}(+)[5,7,22$, $30,31]$. The review of 1,564 cases from the Memorial Sloan-Kettering Cancer Center in the U.S.A. reported that only $13 \%$ of patients who underwent laparoscopic prostatectomy had positive surgical margins [30]. Similar results were observed in research from Harvard [31]. In a recent study of 95 men who underwent robot-assisted laparoscopic radical prostatectomy with BNP, the overall SM(+) rate was $14.7 \%$ [22]. Generally, in more recent reports, the observed better oncological outcome can likely be attributed to the better surgical technique, and the earlier tumour detection, but also to the low rate of extracap- sular disease [7]. In our study, the overall positive surgical margin rate was relatively high. This is most likely associated with at least twice greater frequency of extracapsular disease present in our patients (40.33\%) than reported in other series with lower $\mathrm{SM}(+)$ rates (4.5-27\%) [5, 7, 30-32]. It should be emphasized that the use of radical prostatectomy for high-risk PCa and the use of minimally invasive treatment alternatives for low-risk disease have become more popular in many countries in Europe and the U.S.A. over the last decade $[33,34]$. It is likely that this trend will continue, and the patients with very low-risk disease or men older than 70 years who are candidates for active surveillance will select minimally invasive surgery, whereas in the high-risk group, indications for radical prostatectomy may expand, because this surgery with extended pelvic lymph node dissection might improve the oncological outcome [35]. Further polarization of radical prostatectomy into a minimally invasive procedure with the goal of preserving function or extensively radical prostatectomy aiming to achieve extensive resection will possibly become more distinct in future.

In our study, we demonstrated that the anatomic dissection with preservation of the bladder neck is an oncologically safe procedure. Although there were 14 patients with a positive bladder neck margin, the great majority $(12 / 14)$ had $S M(+)$ at multiple sites, indicating that a positive surgical margin would have occurred regardless of bladder neck preservation.

In the present study, factors correlating with cancer aggressiveness (i.e. preoperative PSA and pathological T stage) were independently associated with an increased risk of SM(+). Whereas some previous groups have also identified those two factors as predictors of positive margins, others did not confirm any correlation with $\mathrm{SM}(+)$ and indicated the biopsy Gleason score, clinical T stage, prostate volume, interfascial neurovascular bundle dissection and body mass index to be independent predictors of $\mathrm{SM}(+)$ [22, 25, 36, 37].

In this study the presence of positive surgical margins significantly affected the 3-year biochemical recurrence-free survival rate $(55.8 \%$ vs. $89.9 \%$ in $\mathrm{SM}(+)$ and $\mathrm{SM}(-)$, respectively, $p<0.001)$. The effect of positive surgical margins status on 3-year biochemical recurrence-free survival rates was particularly pronounced in those with preoperative PSA > $10 \mathrm{ng} / \mathrm{ml}$ (39.2\% vs. 65.4\% in men with PSA $\leq 10 \mathrm{ng} /$ $\mathrm{ml}, p=0.027)$. Although there were no such analyses 
performed in previously reported studies describing results of laparoscopic radical prostatectomy with bladder neck preservation, the importance of the positive surgical margins and preoperative PSA level on the risk of biochemical recurrence has been well recognised [38-40].

It is well known that $S M(+)$ s significantly increase the risk of $B C R$. However, there is a lack of association between positive margins and cancer-specific mortality (CSM), which is likely due to the highly variable natural history of biochemical recurrence. The data evaluating the risk of metastatic progression and death in men with $\mathrm{SM}(+)$ and $\mathrm{BCR}$ have stressed the importance of other adverse clinical and pathological parameters than just the presence of positive margins alone, as absence of those features in men with $\mathrm{SM}(+) \mathrm{s}$ may be associated with an indolent form of BCR [41]. In a recent, large population-based study using the Surveillance Epidemiology and End Results (SEER) cancer registry, in which patients were followed for a median of 4.2 years, a 1.7-fold increased risk of death from PCa was observed among men with positive compared with negative surgical margins [42]. However, after adjustments for adverse pathological features, these findings held true for only high-grade tumours or extraprostatic disease (pT3). Another study by Chalfin et al. showed that an $\mathrm{SM}(+)$ was an independent predictor of prostate-cancer-specific mortality (hazard ratio (HR) was 1.4), but the impact was of a modest effect compared to the Gleason score $(H R=5.7-12.6)$ and pathological stage $(H R=2.2-11.0)$ [43]. Several other studies have failed to identify $S M(+) s$ to be associated with an increased risk of systemic progression and cancer-specific mortality [44-46]. Similarly, the most recent report with the longest follow-up indicated that $S M(+) s$ alone were not associated with a significantly increased risk of CSM within 15 years [47]. In this study men with SM(+) had 1.04-fold risk of death from PCa compared to those with negative surgical margins.

For the time being, it remains unclear why positive surgical margins may affect probability of BCR but not distant metastasis or cancer-specific mortality, particularly as SM(+)s increase the risk of disease recurrence [48]. It is likely that competing causes of mortality may obscure the detrimental impact of SM(+)s on death due to PCa $[46,49]$. However, urologists should strive to avoid positive surgical margins, as they increase the risk of BCR and consequently the need for secondary treatment and may be a source of anxiety among affected patients $[50,51]$.

The present study has some limitations. Our research is retrospective and it is, therefore, subject to bias and limitations frequently associated with this type of study. Moreover, we have not analysed the effect of size of the prostate, and the presence of a large middle lobe on the functional outcomes. In addition, median follow-up was relatively short (3 years), and consequently the sample size analysed at 12, 24 and 36 months of follow-up was relatively small. Additionally, data regarding postoperative urinary continence at 12 months of follow-up were available in 196 out of 295 patients who underwent the surgery.

\section{Conclusions}

Laparoscopic radical extraperitoneal prostatectomy with bladder neck preservation proved to be a safe procedure resulting in a good functional outcome. We observed a relatively high incidence of positive surgical margins. This could be attributed to a large number of extracapsular disease cases. The data regarding the prognostic factors for positive surgical margins identified in our study are the same as noted previously in the series describing LRP with BNP. Further prospective research is warranted to further investigate the effect of the size of the prostate, and the presence of a large middle lobe on the functional outcomes following laparoscopic radical prostatectomy with bladder neck sparing.

\section{References}

1. Heidenreich A, Bastian PJ, Bellmunt J, et al. EAU guidelines on prostate cancer. Part 1: screening, diagnosis, and local treatment with curative intent-update 2013. Eur Urol 2014; 65: 124-37.

2. Phillips R. Prostate cancer: post-treatment complications of radiotherapy and prostatectomy. Nat Rev Urol 2014; 11: 129.

3. Sacco E, Prayer-Galetti T, Pinto F, et al. Urinary incontinence after radical prostatectomy: incidence by definition, risk factors and temporal trend in a large series with a long-term follow-up. BJU Int 2006; 97: 1234-41.

4. Young MD, Weizer AZ, Silverstein AD, et al. Urinary continence and quality of life in the first year after radical perineal prostatectomy. J Urol 2003; 170: 2374-8.

5. Froehner M, Koch R, Leike S, et al. Urinary tract-related quality of life after radical prostatectomy: open retropubic versus robot-assisted laparoscopic approach. Urol Int 2013; 90: 36-40.

6. Schuessler WW, Kavoussi LR, Clayman RV, Vancaillie TH. Laparoscopic radical prostatectomy: initial case report. J Urol 1992; 147: 246A, Abstract No. 130. 
7. Chłosta PL, Drewa T, Jaskulski J, et al. Bladder neck preservation during classic laparoscopic radical prostatectomy - point of technique and preliminary results. Videosurgery Miniinv 2012; 7: 89-95.

8. Golabek T, Jarecki P, Jaskulski J, et al. Modified technique for laparoscopic running vesicourethral anastomosis. Videosurgery Miniinv 2014; 9: 357-61.

9. Carlucci JR, Nabizada-Pace F, Samadi DB. Robot-assisted laparoscopic radical prostatectomy: technique and outcomes of 700 cases. Int J Biomed Sci 2009; 5: 201-8.

10. Choi WW, Freire MP, Soukup JR, et al. Nerve-sparing technique and urinary control after robot-assisted laparoscopic prostatectomy. World J Urol 2011; 29: 21-7.

11. Stolzenburg JU, Kallidonis P, Hicks J, et al. Effect of bladder neck preservation during endoscopic extraperitoneal radical prostatectomy on urinary continence. Urol Int 2010; 85: 135-8.

12. Friedlander DF, Alemozaffar M, Hevelone ND, Lipsitz SR, Hu JC. Stepwise description and outcomes of bladder neck sparing during robot-assisted laparoscopic radical prostatectomy. J Urol 2012; 188: 1754-60.

13. Gomez CA, Soloway MS, Civantos F, Hachiya T. Bladder neck preservation and its impact on positive surgical margins during radical prostatectomy. Urology 1993; 42: 689-93.

14. Selli C, De Antoni P, Moro U, et al. Role of bladder neck preservation in urinary continence following radical retropubic prostatectomy. Scand J Urol Nephrol 2004; 38: 32-7.

15. Avery K, Donovan J, Peters T, et al. ICIQ: a brief and robust measure for evaluating the symptoms and impact of urinary incontinence. Neurourology and Urodynamics 2004; 23: 322-30.

16. Warwick RT. Observations on the function and dysfunction of the sphincter and detrusor mechanisms. Urol Clin North Am 1979; 6: 13-30.

17. Tanagho EA, Smith DR. The anatomy and function of the bladder neck. Br J Urol 1966; 38: 54-71.

18. Foote J, Yun S, Leach GE. Postprostatectomy incontinence. Pathophysiology, evaluation, and management. Urol Clin North Am 1991; 18: 229-41.

19. Raz S. Pathophysiology of male incontinence. Urol Clin North Am 1978; 5: 295-304.

20. Carlson KV, Nitti VW. Prevention and management of incontinence following radical prostatectomy. Urol Clin North Am 2001; 28: 595-612.

21. Bianco FJ, Grignon DJ, Sakr WA, et al. Radical prostatectomy with bladder neck preservation: impact of a positive margin. Eur Urol 2003; 43: 461-6.

22. Nyarangi-Dix JN, Radtke JP, Hadaschik B, et al. Impact of complete bladder neck preservation on urinary continence, quality of life and surgical margins after radical prostatectomy: a randomized, controlled, single blind trial. J Urol 2013; 189: 891-8.

23. Patel VR, Coelho RF, Chauhan S, et al. Continence, potency and oncological outcomes after robotic-assisted radical prostatectomy: early trifecta results of a high-volume surgeon. BJU Int 2010; 106: 696-702.

24. Jurczok $A$, Zacharias $M$, Wagner $S$, et al. Prospective non-randomized evaluation of four mediators of the systemic response after extraperitoneal laparoscopic and open retropubic radical prostatectomy. BJU Int 2007; 99: 1461-6.
25. Terakawa T, Miyake H, Tanaka K, et al. Surgical margin status of open versus laparoscopic radical prostatectomy specimens. Int J Urol 2008; 15: 704-7.

26. Shelfo SW, Obek C, Soloway MS. Update on bladder neck preservation during radical retropubic prostatectomy: impact on pathologic outcome, anastomotic strictures, and continence. Urology 1998; 51: 73-8.

27. Deliveliotis C, Protogerou V, Alargof E, Varkarakis J. Radical prostatectomy: bladder neck preservation and puboprostatic ligament sparing: effects on continence and positive margins. Urology 2002; 60: 855-8.

28. Poon M, Ruckle H, Bamshad BR, et al. Radical retropubic prostatectomy: bladder neck preservation versus reconstruction. J Urol 2000; 163: 194-8.

29. McNeill SA, Good DW, Stewart GD, Stolzenburg JU. Five-year oncological outcomes of endoscopic extraperitoneal radical prostatectomy (EERPE) for prostate cancer: results from a medium-volume UK centre. BJU Int 2014; 113: 449-57.

30. Touijer K, Secin FP, Cronin AM, et al. Oncologic outcome after laparoscopic radical prostatectomy: 10 years of experience. Eur Urol 2009; 55: 1014-9.

31. Freire MP, Weinberg AC, Lei Y, et al. Anatomic bladder neck preservation during robotic-assisted laparoscopic radical prostatectomy: description of technique and outcomes. Eur Urol 2009; 56: $972-80$

32. Rozet F, Jaffe J, Braud G, et al. A direct comparison of robotic assisted versus pure laparoscopic radical prostatectomy: a single institution experience. J Urol 2007; 178: 478-82.

33. Gallina A, Chun FK, Suardi N, et al. Comparison of stage migration patterns between Europe and the USA: an analysis of 11 350 men treated with radical prostatectomy for prostate cancer. BJU Int 2008; 101: 1513-8.

34. Budäus L, Spethmann J, Isbarn H, et al. Inverse stage migration in patients undergoing radical prostatectomy: results of 8916 European patients treated within the last decade. BJU Int 2011; 108: 1256-61.

35. Briganti A, Blute ML, Eastham JH, et al. Pelvic lymph node dissection in prostate cancer. Eur Urol 2009; 55: 1251-65.

36. Patel VR, Coelho RF, Rocco B, et al. Positive surgical margins after robotic assisted radical prostatectomy: a multi-institutional study. J Urol 2011; 186: 511-6.

37. Secin FP, Serio A, Bianco FJ Jr, et al. Preoperative and intraoperative risk factors for side-specific positive surgical margins in laparoscopic radical prostatectomy for prostate cancer. Eur Urol 2007; 51: 764-71.

38. Han M, Partin AW, Piantadosi S, et al. Era specific biochemical recurrence-free survival following radical prostatectomy for clinically localized prostate cancer. J Urol 2001; 166: 416-9.

39. Hull GW, Rabbani F, Abbas F, et al. Cancer control with radical prostatectomy alone in 1,000 consecutive patients. J Urol 2002; 167: 528-34

40. Guillonneau B, el-Fettouh H, Baumert H, et al. Laparoscopic radical prostatectomy: oncological evaluation after 1,000 cases a Montsouris Institute. J Urol 2003; 169: 1261-6.

41. Freedland SJ, Humphreys EB, Mangold LA, et al. Death in patients with recurrent prostate cancer after radical prostatectomy: prostate-specific antigen doubling time subgroups and 
their associated contributions to all-cause mortality. J Clin Oncol 2007; 25: 1765-71.

42. Wright JL, Dalkin BL, True LD, et al. Positive surgical margins at radical prostatectomy predict prostate cancer specific mortality. J Urol 2010; 183: 2213-8.

43. Chalfin HJ, Dinizo M, Trock BJ, et al. Impact of surgical margin status on prostate-cancer-specific mortality. BJU Int 2012; 110: 1684-9.

44. Pfitzenmaier J, Pahernik S, Tremmel T, et al. Positive surgical margins after radical prostatectomy: do they have an impact on biochemical or clinical progression? BJU Int 2008; 102: 1413-8.

45. Boorjian SA, Karnes RJ, Crispen PL, et al. The impact of positive surgical margins on mortality following radical prostatectomy during the prostate specific antigen era. J Urol 2010; 183: 1003-9.

46. Mauermann J, Fradet V, Lacombe L, et al. The impact of solitary and multiple positive surgical margins on hard clinical end points in 1712 adjuvant treatment-naive pT2-4 NO radical prostatectomy patients. Eur Urol 2013; 64: 19-25.

47. Stephenson AJ, Eggener SE, Hernandez AV, et al. Do margins matter? The influence of positive surgical margins on prostate cancer-specific mortality. Eur Urol 2014; 65: 675-80.

48. Corcoran NM, Hovens CM, Metcalfe C, et al. Positive surgical margins are a risk factor for significant biochemical recurrence only in intermediate-risk disease. BJU Int 2012; 110: 821-7.

49. Thompson IM, Tangen CM, Paradelo J, et al. Adjuvant radiotherapy for pathological T3NOMO prostate cancer significantly reduces risk of metastases and improves survival: long-term follow-up of a randomized clinical trial. J Urol 2009; 181: 956-62.

50. Hong YM, Hu JC, Paciorek AT, et al. Impact of radical prostatectomy positive surgical margins on fear of cancer recurrence: results from CaPSURE. Urol Oncol 2010; 28: 268-73.

51. Trock BJ, Han M, Freedland SJ, et al. Prostate cancer-specific survival following salvage radiotherapy vs observation in men with biochemical recurrence after radical prostatectomy. JAMA 2008; 299: 2760-9.

Received: 24.10.2013, accepted: 22.07.2014. 